\title{
FAKTOR-FAKTOR YANG BERHUBUNGAN DENGAN PERILAKU MEROKOK PADA REMAJA DI NANGA BULIK
}

\author{
Gopie Elpasa1 $^{1}$, Lina Dewi Anggraeni ${ }^{2}$, dan Jesika Pasaribu ${ }^{3}$ \\ 1,2,3 Sekolah Tinggi Ilmu Kesehatan Sint Carolus, linadewiam@gmail.com
}

\begin{abstract}
ABSTRAK
Latar Belakang : Merokok merupakan salah satu perilaku yang merugikan kesehatan baik bagi diri sendiri dan orang lain, akan tetapi masih banyak orang yang merokok bahkan usia merokok paling banyak didapati pada usia remaja.

Tujuan : Penelitian ini bertujuan untuk mengetahui faktor-faktor yang berhubungan dengan perilaku merokok pada remaja di Nanga Bulik.

Metode : Penelitian ini menggunakan metode kuantitatif dengan pendekatan cross sectional, yang dilakukan pada bulan Juli-Agustus 2020Teknik pengambilan sampel adalah purposive sampling sebanyak 82 responden. Analisis statistik yang digunakan uji Kendall's Tau B.

Hasil : Hasil penelitian menunjukkan sebanyak $75.6 \%$ remaja memiliki pengetahuan yang baik, $72 \%$ sikap yang positif, $64.6 \%$ adanya pengaruh dari orang tua, $86.6 \%$ adanya pengaruh teman sebaya, dan $53.7 \%$ memilki perilaku merokok yang baik. Dalam uji hubungan menunjukkan bahwa adanya hubungan, variabel yang berhubungan yaitu pengaruh orang tua $(p$ value $=0.008)$ dan pengaruh teman sebaya ( $p$ value $=0.000)$.

Simpulan : Terdapat hubungan pengaruh orang tua dan teman sebaya dengan perilaku merokok. Remaja diharapkan mendapatkan informasi dan mengikuti sosialisasi mengenai bahaya merokok agar terhindar dari bahaya yang mengancam kesehatan dan pentingnya pengawasan dari orang tua dalam pergaulan anaknya.
\end{abstract}

Kata kunci : perilaku merokok, remaja, teman sebaya

\begin{abstract}
Background: Smoking is one of the behaviors that harm health both for ourself and others, but there are still many people who smoke even the most smoking age in adolescence.
\end{abstract}

Objective: This study aims to find out the factors related to smoking behavior in adolescents in Nanga Bulik 
Methods: This study used quantitative method with cross sectional approach, which was conducted in July-August 2020 Sampling technique is purposive sampling as many as 82 respondents. Statistical analysis used the Kendall's Tau B test.

Result: The results showed that $75.6 \%$ of adolescents have good knowledge, $72 \%$ have positive attitudes, $64.6 \%$ have influences from parents, $86.6 \%$ have peer influence, and $53.7 \%$ have good smoking behavior.

There is significant correlation between parental influence $(\mathrm{p}$ value $=0.008)$ and peer influence $(\mathrm{p}$ value $=0.000)$ with smooking behaviour.

Conclusion: There is a relationship of influence of parents and peers with smoking behavior. Teenagers are expected to get information and follow socialization about the dangers of smoking in order to avoid dangers that threaten health and the importance of parental supervision in their children's association.

Keyword's : smoking behavior, teens, peers

\section{PENDAHULUAN}

$\begin{array}{rrr}\text { Menurut } & \text { World } & \text { Health } \\ \text { Organization } & \text { (WHO), } & \text { remaja }\end{array}$
merupakan penduduk dengan rentang usia 10-19 tahun. Remaja merupakan masa transisi dari anak-anak menjadi dewasa. Pada fase ini berbagai perubahan terjadi baik perubahan hormonal, fisik, psikologis, maupun sosial. Perubahan ini terjadi dengan sangat cepat tanpa disadari (Sudarwan, Arkhaesi, \& Anam, 2019).

Masa remaja cenderung memiliki ketidakstabilan, baik dalam pemikiran dan pegangan prinsip hidup. Pengaruh negatif interaksi sosial dalam pergaulan yaitu sangat erat sekali akan terjadinya perilaku menyimpang yaitu kenakalan remaja. Permasalahan yang sering terjadi pada remaja misalnya, kelompok remaja senang berkumpul suatu tempat (nongkrong) dan hal yang sering mereka lakukan seperti membicarakan tentang lawan jenis, merokok, mabukmabukan, pergaulan bebas dan menggunakan narkoba, minum alkohol, menonton pornografi melalui telepon genggam dan lain sebagainya (Sigalingging \& Sianturi, 2019).

Salah satu kenakalan remaja saat ini yaitu perilaku merokok, merokok tidak hanya terjadi pada orang dewasa, tetapi juga menjadi gaya hidup di kalangan para remaja. Hasil dari Riset Kesehatan Dasar (Riskesdas, 2018), perilaku merokok pada penduduk Indonesia usia 10 sampai 18 tahun masih belum terjadi penurunan dari 2013 hingga 2018. Angka ini bahkan cenderung mengalami 
peningkatan dari $7,2 \%$ pada tahun 2013, menjadi $8,8 \%$ pada tahun 2016 , serta 9,1\% pada tahun 2018 (Kementerian Kesehatan Republik Indonesia, 2018).

Perilaku merokok pada umumnya dilakukan remaja agar tampak dewasa, kebiasaan merokok mulai pada usia remaja dan percobaan merokok tersebut berkembang menjadi pengguna secara bertahap hingga menjadi kebiasaan. Perilaku merokok lebih besar oleh laki-laki dibandingkan perempuan karena perbedaan signifikan antara laki-laki dengan perempuan dalam hal keyakinan akan bahaya perilaku merokok dan penolakan terhadap perilaku merokok dan juga frekuensi saat merokok. Pengetahuan yang kurang terhadap dampak bagi kesehatan dan berbagai penyakit yang disebabkan oleh rokok, dan keingintahuan remaja terhadap rokok membuat remaja tertarik (Widianti \& Wahyono, 2014) . Pengaruh teman sebaya dan orang tua sangat signifikan pada perilaku merokok pada remaja, tetapi pengaruh teman sebaya lebih besar dibandingkan pengaruh dari orang tua (Sitorus, 2017).
Berdasarkan hasil observasi dan wawancara yang dilakukan terhadap sejumlah remaja di Nanga Bulik, remaja tersebut menyatakan bahwa sudah terbiasa merokok dalam kondisi dan aktivitas apapun. Para remaja merasa bahwa dengan merokok bersama dapat meningkatkan rasa percaya diri mereka, remaja tersebut juga tidak memikirkan dan tidak tahu dampak dari merokok apa lagi ketika sedang melakukan aktivitas berat.

\section{METODE PENELITIAN}

Penelitian ini adalah penelitian kuantitatif dengan desain deskriptif korelatif menggunakan pendekatan cross sectional. Penelitian dilakukan pada Bulan Juli-Agustus 2020. Sasaran penelitian ini adalah remaja yang merokok remaja di Nanga Bulik sebanyak 82 responden. Pengambilan sampel ini dilakukan menggunakan teknik purposive sampling, dengan kriteria inklusi remaja berusia 12-21 tahun, dan remaja yang merokok (bukan rokok elektrik). 
Gopie Elpasa, Lina Dewi Anggraeni, dan Jesika Pasaribu Faktor-Faktor yang Berhubungan denganPerilaku Merokok pada Remaja di Nanga Bulik

\section{HASIL DAN PEMBAHASAN}

Tabel 1

Distribusi Frekuensi Pengetahuan, Sikap, Pengaruh Orang Tua, Teman Sebaya, dan Perilaku Merokok

\begin{tabular}{lcc}
\hline \multicolumn{1}{c}{ variabel } & $\mathrm{n}$ & $\%$ \\
\hline Pengetahuan & & \\
Baik $>25$ & 62 & 75.6 \\
Kurang baik $<25$ & 20 & 24.4 \\
\hline Sikap & & \\
Positif $>41$ & 59 & 72.0 \\
Negatif $<41$ & 23 & 28.0 \\
\hline Pengaruh Orang tua & & \\
Ada $>22$ & 53 & 64.6 \\
Tidak ada $<22$ & 29 & 35.4 \\
\hline Pengaruh Teman Sebaya & & \\
Ada $>20,5$ & 71 & 86.6 \\
Tidak ada $<20,5$ & 11 & 13.4 \\
Perilaku Merokok & & \\
Buruk $>23$ & 44 & 53.7 \\
Sangat Buruk $<23$ & 38 & 46.3 \\
\hline \multicolumn{1}{c}{ Total } & 82 & 100.0 \\
\hline
\end{tabular}

Tabel 1 menunjukkan bahwa pengetahuan responden tentang perilaku merokok baik yaitu sebesar 62 responden $(75,6 \%)$, memiliki sikap positif sebanyak 59 responden (53\%), ada pengaruh orang tua sebesar 53 responden (64.6\%), ada pengaruh teman sebaya sebanyak 71 responden (86.8\%), dan perilaku merokok buruk sebanyak 44 responden (53.7\%).

Hal ini menjelaskan bahwa sebagian besar responden sudah cukup mengerti dan memahami mengenai merokok dan perilaku merokok. Pengetahuan atau kogitif merupakan domain yang sangat penting untuk terbentuknya tindakan seseorang. Pengetahuan yang baik dapat membantu para remaja agar bisa menelaah mana yang baik dan tidak untuk dirinya sendiri.

Tabel 2

Hubungan Pengetahuan dengan

Perilaku Merokok Remaja di Nanga Bulik

\begin{tabular}{|c|c|c|c|c|c|c|c|}
\hline \multirow{3}{*}{$\begin{array}{c}\text { Pengetah } \\
\text { uan }\end{array}$} & \multicolumn{4}{|c|}{ Perilaku merokok } & \multicolumn{2}{|c|}{ Total } & \multirow[t]{3}{*}{$\begin{array}{l}\text { Va } \\
\text { lue }\end{array}$} \\
\hline & \multicolumn{2}{|c|}{ Buruk } & \multicolumn{2}{|c|}{$\begin{array}{l}\text { Sangat } \\
\text { Buruk }\end{array}$} & $\mathbf{N}$ & $\%$ & \\
\hline & $\mathbf{N}$ & $\%$ & $\mathbf{N}$ & $\%$ & & & \\
\hline Baik $>25$ & 37 & 59.7 & 25 & 40.3 & 62 & 100 & \\
\hline $\begin{array}{c}\text { Kurang } \\
\text { baik }<25\end{array}$ & 7 & 35 & 13 & 65 & 20 & 100 & $\begin{array}{c}0.0 \\
53\end{array}$ \\
\hline Total & 44 & 53.7 & 38 & 46.3 & 82 & 100 & \\
\hline
\end{tabular}

Tabel 2 menunjukkan bahwa mayoritas responden dengan pengetahuan baik 37 responden $(59.7 \%)$ dengan perilaku merokok buruk. Hasil uji kendall's tau $B$ didapatkan nilai $\mathrm{P}$ value $0,053(>0,05)$. Ini berarti tidak ada hubungan antara pengetahuan dan perilaku merokok pada remaja di Kelurahan Nanga Bulik. Hasil penelitian ini sejalan dilakukan oleh Adam, Rattu, dan Maddusa (2019) mengemukakan bahwa tidak ada hubungan bermakna dengan pengetahuan dan perilaku merokok dengan p-value 0,669, kurangnya informasi yang tersedia di lingkungan sekitar rumah tentang rokok pada remaja di desa Nanga Bulik sehingga para remaja tidak mengetahui bahaya 
yang akan terjadi apabila remaja tersebut merokok.

Tabel 3

Hubungan Sikap dengan Perilaku

Merokok Remaja

di Nanga Bulik

\begin{tabular}{|c|c|c|c|c|c|c|c|}
\hline \multirow{3}{*}{ Sikap } & \multicolumn{3}{|c|}{ Perilaku merokok } & \multicolumn{3}{|c|}{ Total } & \multirow{2}{*}{ Value } \\
\hline & Burul & & $\begin{array}{l}\text { Sangat } \\
\text { Buruk }\end{array}$ & $t$ & $\%$ & & \\
\hline & $\mathbf{N}$ & $\%$ & $\mathbf{N}$ & $\%$ & & & \\
\hline $\begin{array}{l}\text { Positif }> \\
41\end{array}$ & 32 & 54.2 & 27 & 45.8 & 59 & 100 & \\
\hline $\begin{array}{l}\text { Negatif } \\
<41\end{array}$ & 12 & 52.2 & 11 & 47.8 & 23 & 100 & 0.866 \\
\hline Total & 44 & 53.7 & 38 & 46.3 & 82 & 100 & \\
\hline
\end{tabular}

Tabel 3 menununjukkan bahwa mayoritas responden dengan sikap positif 32 responden $(54.2 \%)$ dengan perilaku merokok buruk. Hasil uji kendall's tau $B$ didapatkan nilai P $0,866(>0,05)$. Ini berarti tidak ada hubungan antara sikap dan perilaku merokok pada remaja di Kelurahan Nanga Bulik.

Hasil penelitian ini tidak sejalan dengan penelitian yang dilakukan oleh Elbands dan Noviansyah (2020) yang menyatakan ada hubungan antara sikap dan perilaku merokok dengan p-value 0,001. Sikap seorang remaja terhadap perilaku merokok bahwa dengan merokok akan meningkatkan tingkat kepercayaan diri responden serta akan terlihat gaul padahal pemikiran seperti itu merupakan suatu hal yang keliru.

Sikap remaja terhadap perilaku merokok pada umumnya semakin lama akan semakin meningkat sesuai dengan tahap perkembangan yang ditandai dengan meningkatnya intensitas merokok serta akan membuat ketergantungan akibat nikotin yang terkandung di dalam rokok (Elbands \& Noviansyah, 2020) . Sikap positif terhadap perilaku merokok akan cenderung membuat niat seseorang untuk berhenti merokok rendah dan sikap negatif terhadap perilaku merokok akan cenderung membuat niat seseorang berhenti merokok tinggi.

Tabel 4

Hubungan Pengaruh Orang Tua dengan Perilaku Merokok Remaja di Nanga Bulik

\begin{tabular}{|c|c|c|c|c|c|c|c|}
\hline \multirow{3}{*}{$\begin{array}{c}\text { Pengaruh } \\
\text { Orang } \\
\text { Tua }\end{array}$} & \multicolumn{3}{|c|}{ Perilaku merokok } & \multicolumn{2}{|c|}{ Total } & \multirow{2}{*}{\multicolumn{2}{|c|}{ Value }} \\
\hline & \multirow{2}{*}{$\frac{\text { Buruk }}{\mathbf{N}}$} & \multicolumn{2}{|c|}{$\begin{array}{l}\text { Sangat } \\
\text { Buruk }\end{array}$} & \multirow{2}{*}{$\begin{array}{l}\mathbf{N} \\
\%\end{array}$} & \multirow[t]{2}{*}{$\%$} & & \\
\hline & & $\%$ & $\mathbf{N}$ & & & & \\
\hline Ada $>22$ & 34 & 64.2 & 19 & 35.8 & 53 & 100 & \\
\hline $\begin{array}{l}\text { Tidak ada } \\
<22\end{array}$ & 10 & 34.5 & 19 & 65.5 & 29 & 100 & 0.008 \\
\hline Total & 44 & 53.7 & 38 & 46.3 & 82 & 100 & \\
\hline
\end{tabular}

Tabel 4 menunjukkan bahwa bahwa ada pengaruh orang tua 34 responden $(64.2 \%)$ dengan perilaku merokok buruk. Hasil uji kendall's tau $B$ didapatkan nilai P $0,008 \quad(>0,05)$. Maka dapat diartikan ada hubungan 
Gopie Elpasa, Lina Dewi Anggraeni, dan Jesika Pasaribu Faktor-Faktor yang Berhubungan denganPerilaku Merokok pada Remaja di Nanga Bulik

antara pengaruh orang tua dan perilaku merokok pada remaja di Kelurahan Nanga Bulik.

Sejalan dengan penelitian yang dilakukan oleh Sulistyawa (2012) menunjukkan ada hubungan antara pengaruh orang tua dengan perilaku merokok dengan nilai $\mathrm{P} \quad 0,000$. Remaja yang memiliki orang tua yang merokok akan berpeluang hampir 5 kali untuk anak mereka mengikuti jejak orang tua mereka untuk merokok dibandingkan dengan anak yang memiliki orang tua yang tidak merokok. Menurut King (2016) mengatakan pola asuh yang salah dari orang tua dapat menyebabkan anaknya terjerumus kedalam perbuatan yang menyimpang seperti merokok, memakai obat-obatan terlarang serta pergaulan bebas.

Tabel 5

Hubungan Pengaruh Teman Sebaya dengan Perilaku Merokok Remaja di Nanga Bulik

\begin{tabular}{|c|c|c|c|c|c|c|c|}
\hline \multirow{3}{*}{$\begin{array}{c}\text { Penngaru } \\
\text { h Teman } \\
\text { Sebaya }\end{array}$} & \multicolumn{4}{|c|}{ Perilaku merokok } & \multicolumn{2}{|c|}{ Total } & \multirow{3}{*}{$\begin{array}{c}\text { Valu } \\
\text { e }\end{array}$} \\
\hline & \multicolumn{2}{|c|}{ Buruk } & \multicolumn{2}{|c|}{$\begin{array}{l}\text { Sangat } \\
\text { Buruk }\end{array}$} & \multirow{2}{*}{$\mathbf{N}$} & \multirow{2}{*}{$\%$} & \\
\hline & $\mathbf{N}$ & $\%$ & $\mathbf{N}$ & $\%$ & & & \\
\hline Ada $>20$ & $\begin{array}{l}3 \\
3\end{array}$ & $\begin{array}{c}46 . \\
5\end{array}$ & $\begin{array}{l}3 \\
8\end{array}$ & $\begin{array}{c}53 . \\
5\end{array}$ & $\begin{array}{l}7 \\
1\end{array}$ & $\begin{array}{c}10 \\
0\end{array}$ & \\
\hline $\begin{array}{l}\text { Tidak ada } \\
<19\end{array}$ & $\begin{array}{l}1 \\
1\end{array}$ & $\begin{array}{c}53 . \\
7\end{array}$ & 0 & $\begin{array}{c}46 . \\
3\end{array}$ & $\begin{array}{l}1 \\
1\end{array}$ & $\begin{array}{c}10 \\
0\end{array}$ & $\begin{array}{c}0.00 \\
0\end{array}$ \\
\hline Total & $\begin{array}{l}4 \\
4\end{array}$ & 100 & $\begin{array}{l}3 \\
8\end{array}$ & 100 & $\begin{array}{l}8 \\
2\end{array}$ & $\begin{array}{c}10 \\
0\end{array}$ & \\
\hline
\end{tabular}

Tabel 5 menunjukkan bahwa ada pengaruh teman sebaya 38 responden $(53.5 \%)$ dengan perilaku merokok sangat buruk. Hasil uji kendall's tau $\mathrm{B}$ didapatkan nilai $\mathrm{P}$ $0,000(>0,05)$. Ini berarti ada hubungan antara pengaruh teman sebaya dan perilaku merokok pada remaja di Kelurahan Nanga Bulik.

Hasil penelitian sejalan yang dilakukan oleh (Riadinata, 2018) bahwa pengaruh teman sebaya mempunyai pengaruh dalam perilaku merokok remaja. Perilaku merokok disebabkan oleh beberapa faktor salah satunya faktor psikososial, faktor ini berhubungan langsung dengan perilaku merokok di usia remaja yang diantaranya yaitu stres dan efek negative, teman sebaya, proses coping dan keluarga.

Remaja menganggap bahwa rokok adalah salah satu alat yang menunjukkan bahwa mereka tampak bebas dan dewasa saat mereka mencoba menyesuaikan diri mereka pada lingkungan sosial. Remaja yang pandai menempatkan dirinya pada lingkungan teman sebaya yang baik dapat mengembangkan identitas dirinya yang positif. 


\section{KESIMPULAN DAN SARAN}

\section{Kesimpulan}

Orang tua memiliki pengaruh terhadap perilaku remaja, khusunya perilaku merokok. Hal ini disebakan karena orang tua merupakan model peran bagi anak mereka, misalnya orang tua mereka perokok berat, maka anak-anaknya akan mungkin sekali untuk meniru apa yang dilakukan orang tua mereka dan sebaliknya bila orang tua memberikan dampak positif pada anak-anaknya maka anak-anak akan meniru hal yang baik dalam kehidupan pribadi mereka.

\section{Saran}

Hasil penelitian ini diharapkan dapat menjadi masukan agar edukasi dan sosialisasi mengenai bahaya merokok untuk masyarakat dan para remaja yang masih di bawah umur dapat ditingkatkan. Kegiatan ini dilakukan agar remaja terhindar dari bahayabahaya yang mengancam kesehatannya. peran orang tua untuk selalu mengawasi anak-anaknya dalam pergaulan di lingkungan sekitar tempat tinggal.

\section{DAFTAR PUSTAKA}

Adam, K., Rattu, A., \& Maddusa, S. S. (2019). Faktor-Faktor Yang
Berubungan Dengan Perilaku Merokok Pada Pelajar Di SMA Keristen Ratatotok Kab. Minahasa Tenggara. Jurnal KESMAS , 1-6.

Elbands, E. S., \& Noviansyah. (2020). Faktor-Faktor Yang Berhubungan Dengan Perilaku Merokok Pada Siswa Kelas X Dan XI Di SMA N 1 Mesuji. Jurnal Ilmu Kesehatan Indonesia (JIKSI) , 1-8.

Kementerian Kesehatan RI. (2018). Riset Kesehatan Dasar Riskesdas. Badan Penelitian dan Pengembangan Kesehatan, Kementrian Kesehatan RI.

King, A. L. (2016). Psikologi Umum Sebuah Pandangan Apresiatif (edisi 3). Jakarta selatan. Mcgrawhill education \& Salemba Humanika.

Riandinata, E. (2018). Hubungan Lingkungan Keluarga dan Teman Sebaya Dengan Perilaku Merokok Pada Remaja Usia 18-22 Tahun di Desa Gonilan Kartasura. Surakarta: Universitas Muhammadiah.

Riset Kesehatan Dasar. (2018). Badan Penelitian dan Pengembangan Kesehatan Departemen Kesehatan, Republik Indonesia. Jakarta; Laporan Nasional.

Sigalingging, G., \& Sianturi, I. A. (2019). Hubungan Teman Sebaya Dengan Perilaku Seksual Remaja di SMK Medan Area Medan Sunggal. Jurnal Darma Agung Husada, 9-15.

Sitorus, M. I. (2017). Hubungan Pola Asuh Oorang tua Dengan Perilaku Merokok Remaja Laki- 
Gopie Elpasa, Lina Dewi Anggraeni, dan Jesika Pasaribu Faktor-Faktor yang Berhubungan denganPerilaku Merokok pada Remaja di Nanga Bulik

Laki di SMP Negeri 7 Kota Tebing Tinggi Tahun 2017. Medan: Universitas Sumatera Utara.

Sudarwan, D., Arkhaesi, N., \& Anam, M. (2019). Perbedaan Fungsi Paru Pada Remaja Dengan Obstuctive Sleep Apneu (OSA) dan Tanpa OSA. eprints.undip.ac.id, 7-23.

Widianti, E. V., \& Wahyono, T. M. (2014). Faktor-Faktor Yang Berhubungan Dengan Perilaku Merokok Siswa SMP Negeri
"X" di Kota Bogor Tahun 2014. Jurnal FMK UI, 1-16.

Sulistyawan, A. (2012). Faktor-Faktor Yang Berhubungan Dengan Perilaku Merokok Siswa Sekolah Menengah Pertama Negeri 3 Kota Tangerang Selatan Tahun 2012. Jakarta: Universitas Islam Negeri Syarif Hidayatullah. 